\title{
IMPROVEMENT AND GENERALIZATION OF SOME JENSEN-MERCER-TYPE INEQUALITIES
}

\section{HAMID REZA MORAdi AND SHIGERU FuRUICHI}

Abstract. The present paper is devoted to the study of Jensen-Mercer-type inequalities. Our results generalize and improve some earlier results in the literature.

Mathematics subject classification (2010): 26A51, 26D15, $26 \mathrm{~B} 25$.

Keywords and phrases: Jensen-Mercer inequality, Jensen inequality, convex function.

\section{REFERENCES}

[1] Y.J. Cho, M. MATiĆ AND J. PEČARIĆ, Two mappings in connection to Jensen's inequality, Panamerican Math. J., 12 (2002), 43-50.

[2] S.S. DRAGOMIR, Hermite-Hadamard's type inequalities for convex functions of selfadjoint operators in Hilbert spaces, Linear Algebra Appl., 436(5) (2012), 1503-1515.

[3] M. Kian And M.S. Moslehian, Refinements of the operator Jensen-Mercer inequality, Electron. J. Linear Algebra.,26 (2013), 742-753.

[4] A. Matković, J. PeČArić And I. PERiĆ, A variant of Jensen's inequality of Mercer's type for operators with applications, Linear Algebra Appl., 418 (2006), 551-564.

[5] A. MCD. MERCER, A variant of Jensen's inequality, J. Inequal. Pure Appl. Math., 4(2) (2003), Article 73.

[6] J. MićIĆ AND Y. SEO, An interpolation of Jensen's inequality and its applications to mean inequalities, J. Math. Inequal., 12(2) (2018), 303-313.

[7] H.R. Moradi, S. Furuichi, F.C. Mitroi And R. NAseri, An extension of Jensen's operator inequality and its application to Young inequality, Rev. R. Acad. Cienc. Exactas Fís. Nat. Ser. A Mat, 113(2) (2019), 605-614.

[8] H.R. Moradi, M.E. Omidvar, M. Adil Khan and K. Nikodem, Around Jensen's inequality for strongly convex functions, Aequat. Math, 92 (2018), 25-37. 